TESTIMONIOS DE AFECTO Y AMISTAD

Revista Atlántica-Mediterránea 22, pp. 11-41

BIBLID [2445-3072 (2020) 22, 1-443]

https://doi.org/10.25267/rev_atl-mediterr_prehist_arqueol_soc.2020.v22.03

\title{
LA CONTRIBUCIÓN DE ANTONIO SÁEZ ESPLIGARES A LA ARQUEOLOGÍA PREHISTÓRICA DE SAN FERNANDO EN LOS AÑOS 90 DEL SIGLO XX. TESTIMONIOS DE UNA FRUCTÍFERA COLABORACIÓN
}

\author{
José RAMOS MUÑOZ
}

Catedrático de Prehistoria. Universidad de Cádiz

Correo electrónico: jose.ramos@uca.es

Conocí a Antonio Sáez Espligares poco tiempo después de mi incorporación como profesor de Prehistoria en la Universidad de Cádiz, en el año 1988.

En los comienzos de mi actividad de investigación en Cádiz, me ayudó mucho y fue un magnífico compañero y colaborador.

La Delegación de Cultura de la Junta de Andalucía en Cádiz había realizado excavaciones de urgencia en la zona de Gallineras, de San Fernando en 1989, donde se había localizado una necrópolis romana, asociada a productos cerámicos y líticos prehistóricos.

El recordado y querido amigo Lorenzo Perdigones, arqueólogo provincial de Cádiz, nos ofreció la posibilidad de estudiar los materiales documentados en aquella excavación. Ese fue mi primer contacto con Antonio Sáez, en su oficina situada entonces en el ático del Ayuntamiento de San Fernando, que a la vez era depósito de los fondos y reserva de materiales arqueológicos del futuro Museo de San Fernando. Dicho Museo en aquellos momentos era solo una quimera de la que hablaba con ilusión un ya maduro y muy educado profesional de la Arqueología y Museografía, como era Antonio.

En la gestión y desarrollo de la excavación del yacimiento de El Estanquillo, Antonio, fue clave. Recuerdo que las primeras visitas las hicimos con Antonio Sáez, junto con Vicente Castañeda y Diego Moreno, entonces estudiantes y alumnos de la Facultad de Filosofía y Letras de la Universidad de Cádiz, así como con Francisco Martínez, colaborador y también amigo, valorando la posibilidad de excavación.

La excavación en El Estanquillo fue importante para mí. Era un joven arqueólogo y profesor, recién llegado a una zona diferente a mis orígenes. Conseguimos estratificar dos niveles en sentido normativo: Neolítico y Edad del Bronce. Este yacimiento fue una verdadera escuela de futuros profesionales. De los numerosos estudiantes que entonces participaron en las mismas, hoy hay muchos veteranos arqueólogos y profesores.

Antonio nos ayudó mucho en estos trabajos, en el aporte de infraestructuras, herramientas, apoyo logístico. Su actitud y talante siempre eran las de una persona amable, cordial y muy educado.

El interés por este registro arqueológico de San Fernando y numerosas conversaciones con Antonio Sáez y con Francisco Martínez nos llevaron a valorar unas colecciones de productos arqueológicos, vinculados a sociedades prehistóricas que se encontraban en el mencionado depósito municipal, que habían sido recopilados durante décadas por el propio Antonio y por aficionados interesados en estos temas, y que eran custodiados en el Ayuntamiento.

Ello nos llevó a valorar el potencial de las ocupaciones prehistóricas de San Fernando y a comenzar a formular la idea de un Proyecto General de Investigación titulado La ocupación prehistórica de la campiña litoral y banda atlántica de Cádiz, vinculado al estudio de las sociedades prehistóricas en este territorio. Lo presentamos a la Junta de Andalucía el 30 de octubre de 1991. Comenzamos dicho proyecto por el término municipal de San Fernando, con prospecciones arqueológicas sistemáticas y por la revisión de los materiales documentados en la reserva del depósito municipal del Ayuntamiento.

En el desarrollo de estas tareas de campo, la ayuda de Antonio fue constante. Nos aportaba un gran conocimiento, datos, información básica de la estratificación, de hallazgos líticos y cerámicos.

Visitamos los yacimientos conocidos y se descubrieron nuevos sitios. Los resultados fueron sorprendentes por aquellos años, al comprobar un gran poblamiento al aire libre vinculado a diversas etapas de la ocupación de sociedades prehistóricas, paleolíticas, neolíticas y de la Prehistoria Reciente.

En paralelo estudiamos los materiales depositados en el Ayuntamiento. Fueron numerosas las se- 
siones de estudio en las dependencias, que entonces ya tenían un carácter de Museo emergente. Junto a Antonio Sáez y con la colaboración de los entonces entusiastas estudiantes, Vicente Castañeda, Manuela Pérez, Jorge Cepillo y la ayuda también de Francisco Martínez, se fue generando una información destacada. Antonio aportaba gran ayuda en diseño gráfico, conocimiento de la documentación y de la propia historia de los hallazgos.

El material alcanzó tal envergadura que vimos la posibilidad de generar una monografía. Para mí representaba la consolidación de un modelo de estudios que había aprendido con mis maestros, los profesores de la Universidad de Sevilla, Enrique Vallespí y Oswaldo Arteaga.

Estos resultados de la campaña de prospección y estudio de materiales prehistóricos de San Fernando venían a consolidar con buenas perspectivas un proyecto de investigación que comenzaba y que ocuparía una buena parte de mi dedicación en los años 90 del siglo pasado, en su continuidad en todo el litoral y campiña atlántica de Cádiz. Además representaba la conformación de un equipo de investigación con el que trabajaría durante unos años en el mencionado proyecto.

Los recuerdos de Antonio en aquellos años son siempre agradables, de una persona servicial, amable, siempre dispuesto a colaborar en cualquier faceta de los trabajos: excavación, prospección estudio de materiales en el Museo.

El libro con los resultados de estos trabajos se publicó en 1994, con el título: Aproximación a la Prehistoria de San Fernando. Un modelo de poblamiento periférico en la banda atlántica de Cádiz, y fue editado por el Excmo. Ayuntamiento de San Fernando en la colección de Temas Isleños, con la coordinación en la edición de José Ramos, Antonio Sáez, Vicente Castañeda y Manuela Pérez.

Fruto de esta colaboración conjunta se publicaron también algunos artículos sobre el poblamiento prehistórico de San Fernando en revistas especializadas y en contribuciones a congresos, contando con su colaboración como coautor.

El desarrollo del proyecto continuó en años posteriores en los términos municipales de la campiña y banda litoral atlántica hasta Tarifa.

En los años posteriores continuamos las colaboraciones con el Ayuntamiento de San Fernando y con Antonio Sáez, como auténtico promotor de dichas actividades.

En concreto la labor de Antonio fue decisiva en la organización de las Jornadas de Prehistoria de San Fernando, celebradas en enero de 1995, con la participación de 12 investigadores (José Ramos, Francisco Borja, Francisco Giles, José María Gutiérrez, Eloísa Bernáldez, Alexander Menez, Joaquín Martín, María José Felíu, Manuela Pérez, Vicente Castañeda, Enrique Vallespí, Lorenzo Perdigones) y donde se presentó el libro mencionado: Aproximación a la Prehistoria de San Fernando... Esto suponía una modernización de los conceptos e ideas sobre la visión de la Prehistoria local, con un estudio interdisciplinar universitario, que ya se enmarcaba en los poblamientos regionales del sur de la península Ibérica.

En noviembre de 1995, organizamos conjuntamente también a iniciativa de la Fundación Municipal de Cultura del Ayuntamiento de San Fernando, los XI Encuentros de Historia y Arqueología de San Fernando, con el título: El urbanismo como fenómeno histórico y social. De la aldea neolítica a la ciudad romana, con la participación de ponencias de 6 investigadores expertos en su temática (José Ramos, Francisco Nocete, Pedro Aguayo, Manuel Carrilero, Arturo Ruiz, y Oswaldo Arteaga).

La labor de Antonio fue decisiva en la gestión y organización de otros Encuentros de Historia y Arqueología de San Fernando, que alcanzaron un gran prestigio en los años 90 del siglo pasado, reuniendo a investigadores y especialistas muy reconocidos.

Recordamos especialmente su contribución a la organización de los XIX Encuentros de Historia y Arqueología de San Fernando, con el título Geoarqueología e Historia de la Bahía de Cádiz. Proyecto Antípolis. La Bahía hace 6.500 años, que fueron dirigidos y coordinados por los profesores Oswaldo Arteaga y Horst D. Schulz y la participación de 20 reconocidos investigadores en sus diversos dominios geológicos, geográficos, arqueológicos e históricos (Oswaldo Arteaga, Hors D. Schulz, Anna María Roos, Salvador Domínguez, Javier Gracia, Caridad Zazo, José Ramos, Vicente Castañeda, Manuela Pérez, Diego Ruiz, Gregorio de Frutos, Ángel Muñoz, Manuel Ferreiro, Genaro Chic, Darío Bernal, Aurelio Padilla, Antonio Malpica, Manuel González, Löic Menanteau y Juan Manuel Suarez).

Antonio Sáez ha sido una persona clave durante más de tres décadas en el cuidado y defensa del 
TESTIMONIOS DE AFECTO Y AMISTAD

Revista Atlántica-Mediterránea 22, pp. 11-41

BIBLID [2445-3072 (2020) 22, 1-443]

Patrimonio arqueológico de San Fernando. Ha participado en numerosos proyectos de investigación en todas las etapas históricas de la ocupación humana en San Fernando. Ha trabajado en su difusión y conservación del Patrimonio. Y todo ello con un destacado espíritu de equipo y colaboración.

Como he indicado su apoyo y ayuda en mis comienzos y primeras etapas de trabajo en la arqueología prehistórica en Cádiz, fueron muy importantes. Por todo ello siempre le estaré muy agradecido. Le deseo mucha salud y larga vida, en esta nueva etapa de su jubilación, en compañía de su familia y amigos.

\section{Bibliografía}

RAMOS MUÑOZ, José. 1993: El hábitat prehistórico de "El Estanquillo". Fundación Municipal de Cultura, Ayuntamiento de San Fernando. Cádiz.

RAMOS MUÑOZ, José (coord.). 2008: La ocupación prehistórica de la campiña litoral y banda atlántica de Cádiz. Aproximación al estudio de las sociedades cazadoras-recolectoras, tribales comunitarias y clasistas iniciales. Arqueología Monografías, Junta de Andalucía. Sevilla.

RAMOS MUÑOZ, José; BORJA BARRERA, Francisco; CASTAÑEDA FERNÁNDEZ, Vicente; SÁEZ ESPLIGARES, Antonio; CEPILLO GALVÍN, Jorge y PÉREZ RODRÍGUEZ, Manuela. 1993: “Proyecto: La ocupación prehistórica de la campiña litoral y banda atlántica de Cádiz. Informe de la campaña de prospecciones arqueológicas de 1992 en San Fernando". En J. CAMPOS y F. NOCETE (coords.): Investigaciones arqueológicas en Andalucía. Proyectos, pp. 353-366. Consejería de Cultura Junta de Andalucía. Huelva.

RAMOS MUÑOZ, José; SÁEZ ESPLIGARES, Antonio; CASTAÑEDA FERNÁNDEZ, Vicente y PÉREZ RODRÍGUEZ, Manuela (coords.). 1994: Aproximación a la Prehistoria de San Fernando. Un modelo de poblamiento periférico en la banda atlántica de Cádiz. Colección de Temas Isleños. Excmo. Ayuntamiento de San Fernando. Sevilla.

RAMOS MUÑOZ, José; SÁEZ ESPLIGARES, Antonio; CASTAÑEDA FERNÁNDEZ, Vicente; CEPILLO GALVÍN, Jorge; PÉREZ RODRÍGUEZ, Manuela y GUTIOÉRREZ LÓPEZ, José María. 1993: “La Edad del Bronce de San Fernando. Un modelo de formación económico-social periférico en la Banda Atlántica de Cádiz". Spal, 2, pp. 125-145.

RAMOS MUÑOZ, José; CASTAÑEDA FERNÁNDEZ, Vicente; SÁEZ ESPLIGARES, Antonio; CEPILLO GALVÍN, Jorge y PÉREZ RODRÍGUEZ, Manuela. 1994: "Aproximación al poblamiento neolítico de San Fernando (Cádiz). Inferencias socioeconómicas y enmarque en el contexto regional". Antiquitas, 5, pp. 13-21.

SÁEZ ESPLIGARES, Antonio. 1994: "La historiografía de la Prehistoria y Arqueología clásica en San Fernando". En J. RAMOS; A. SÁEZ; V. CASTAÑEDA y M. PÉREZ (coords.). 1994: Aproximación a la Prehistoria de San Fernando. Un modelo de poblamiento periférico en la banda atlántica de Cádiz, pp. 39-51. Colección de Temas Isleños. Excmo. Ayuntamiento de San Fernando. Sevilla. 